\section{Anaesthetic manage- ment of labour and delivery in a woman taking long-term MAOI}

Timothy J.G. Pavy MBBS FANZCA FRCA DA Dip Mid COG, A. Paul Kliffer MD FRCPC, M. Joanne Douglas MD FRCPC
$A$ case is presented of a woman who, for six years, had been treated for depression with $45 \mathrm{mg}$ daily of the monoamine oxidase inhibitor (MAOI), phenelzine, and who continued taking the drug throughout her pregnancy and labour. Welldocumented and potentially fatal interactions between MAOIs and opioids, notably meperidine, meant that her labour anat gesia needed careful planning. Opioid-and epinephrine-free epidural bupivacaine analgesia was instituted early with small increments of bupivacaine $0.25 \%$ to produce a $T_{10}$ block, afier which an infusion of $8 \mathrm{ml} \cdot \mathrm{hr}^{-1}$ bupivacaine $0.125 \%$ was used to maintain analgesia. After $14 \mathrm{hr}$ labour, the epidural was extended uneventfully to allow Caesarean section to be performed for failure to progress. Pressor agents were avoided as indirect-acting drugs can produce severe hypertension. The child appeared normal and the mother had an uncomplicated postoperative course. Epidural analgesia contributed to the safe conduct of labour and Caesarean delivery.

Une femme a été traitée pour une dépression pendant six ans avec une dose quotidienne de $45 \mathrm{mg}$ de phénelzine, un inhibiteur de la monoamine oxydase (IMAO). Cette médication est continuée pendant la grossesse et le travail. Les interactions bien documentées et potentiellement fatales entre les IMAO et les opiacés, dont la mépéridine, signifient que l'analgésie, pendant le travail, devait être planifiée avec soin. Une épidurale

\section{Key words}

ANAESTHESIA: obstetric;

ANAESTHETIC TECHNIQUES: epidural;

SURGERY: Caesarean section;

ATARACTICS: MAOI, phenelzine.

From the Department of Anaesthesia, Faculty of Medicine, The University of British Columbia and the British Columbia's Women's Hospital, Vancouver, BC, Canada.

Address correspondence to: Dr. Timothy Pavy, Department of Anaesthesia, King Edward Memorial Hospital for Women, 374 Bagot Road, Subiaco, Western Australia 6008.

Accepted for publication 19th March, 1995. à la bupivacaine sans épinéphrine ni morphinique a été mise en marche précocement avec de la bupivacaine $0,25 \%$, administrée en paliers jusqu'à l'obtention d'un bloc à $D_{10}$ après quoi une perfusion de bupivacaine $0,125 \% 8 \mathrm{ml} \cdot \mathrm{h}^{-1}$ a été débutée pour l'entretien de l'analgésie. Après $14 \mathrm{~h}$ de travail, comme celui-ci ne progresse plus, l'épidurale a été complétée sans difficultés pour permettre l'extraction césarienne. On a evité les vasopresseurs parce que les agents $\dot{a}$ action indirecte peuvent provoquer de l'hypertension grave. L'enfant était apparemment normal et la mère n'a pas présenté de complications postopératoires. L'anesthésie épidurale a contribué à l'évolution favorable du travail et à la réalisation de la césarienne.

There has been a resurgence in the popularity of monoamine oxidase inhibitors (MAOI) in the management of depression, especially where tricyclic antidepressants have failed. This presents special difficulties for the anaesthetist. Besides the well-described problems of occasionally lethal excitatory or depressive interactions with meperidine, ${ }^{1,2}$ severe hypertension may be encountered if indirect-acting pressor agents are used to manage hypotension following establishment of a regional block. ${ }^{3}$

There is little known about the effects of MAOIs on the fetus and the neonate. The literature contains no information on analgesia for labour or Caesarean delivery. It is likely tht there will be increased numbers of women taking MAOI who also need analgesia in labour. We report here our experience in the anaesthetic management of labour and delivery in a woman maintained on longterm MAOI.

\section{Case report}

The patient was a 25-yr-old woman who developed a psychotic mood disorder at age $19 \mathrm{yr}$. She was initially treated with imipramine but failed to improve. Subsequently, she responded well to phenelzine $45 \mathrm{mg}$ daily. At $22 \mathrm{yr}$, she voluntarily stopped the drug but rapidly developed deterioration in her mood which required hospitalisation. On a later occasion, reduction of the dose to $30 \mathrm{mg}$ daily led to a marked deterioration in mood. 
She was referred to the Department of Anaesthesia at 37 wk gestation to discuss the implications of her phenelzine therapy on analgesia and anaesthesia for labour and delivery. At the time of referral she was taking 15 $\mathrm{mg}$ in the morning and $30 \mathrm{mg}$ at noon. Her past history included two uneventful general anaesthetics (which included fentanyl) while she was taking phenelzine. She had no allergies and was otherwise healthy.

In view of her past history of deterioration on stopping phenelzine, it was felt that continued treatment was necessary. Early institution of epidural analgesia was recommended as it would offer greater flexibility in the anaesthetic management of this parturient.

At 38 wk gestation, her membranes ruptured spontaneouly and she presented to the labour suite with irregular contractions. Examination revealed a calm, rational woman whose blood pressure was $140 / 80 \mathrm{mmHg}$ measured in the lateral position. She was $162 \mathrm{~cm}$ tall and weighed $80 \mathrm{~kg}$. Fetal presentation was cephalic but the head was high.

After an intravenous bolus of $1000 \mathrm{ml}$ warm normal saline, a 22-g epidural catheter (Portex ${ }^{\circledR}$ ) was inserted under aseptic conditions at the $\mathrm{L}_{2 / 3}$ interspace. A test dose of three $\mathrm{ml}$ bupivacaine $0.25 \%$ without epinephrine was used to exclude intrathecal catheter placement. Two millilitre aliquots of bupivacaine $0.25 \%$ were then injected incrementally into the epidural catheter to obtain a $T_{10}$ level of analgesia (total administered seven millilitres $0.25 \%$ plain bupivacaine). The blood pressure was monitored continuously with a non-invasive vital signs monitor (Dinamap ${ }^{\circledR}, 1846 \mathrm{SX}$, Critikon). Once satisfactory analgesia was established the patient used a patientcontrolled epidural analgesia (PCEA) device (Harvard ${ }^{\circledR}$, Bard) with a continous infusion of eight $\mathrm{ml} \cdot \mathrm{hr}^{-1}$ bupivacaine $0.125 \%$ with a bolus of five $\mathrm{ml}$ and a lockout period of $15 \mathrm{~min}$.

The fetal heart was continuously monitored and the strength of uterine contractions was measured using an intra-uterine pressure catheter (IUPC). The dermatomal level of analgesia was assessed hourly using sensitivity to ice.

During the first hour of epidural analgesia there was a decrease in blood pressure from $140 / 80$ to $100 / 70$ $\mathrm{mmHg}$. The fetal heart was stable and no pharmacotherapy was required. The blood pressure then stabilized at $120 / 80 \mathrm{mmHg}$ with only minor variations for the remainder of the labour.

Six hours after the epidural infusion began, the level of analgesia was at $T_{6}$ on the left and $T_{10}$ on the right and the infusion was stopped for one hour. It was restarted at four $\mathrm{ml} \cdot \mathrm{hr}^{-1}$ and maintained uneventfully for a further eight hours. Progress of labour was slow, despite strong, coordinated uterine contractions and good analgesia. Twenty-eight hours after rupture of the membranes, and $14 \mathrm{hr}$ after institution of epidural analgesia, there was no progress in dilatation of the cervix and the decision was made to deliver the fetus by Caesarean section.

On arrival in the operating room, a radial artery catheter was inserted to provide continuous blood pressure monitoring. Continous ECG and pulse oximetry were also instituted. Left lateral uterine displacement was achieved with an inflatable wedge. Anaesthesia for surgery was obtained by cautious, incremental administration of plain bupivacaine $0.5 \%$ in four millilitre aliquots (total $16 \mathrm{ml}$ ). Warm crystalloid intravenous fluids were administered simultaneously to maintain blood pressure. Oxygen was administered through a mask at four $\mathrm{L} \cdot \mathrm{min}^{-1}$.

A healthy male child was delivered with Apgar scores of nine at one and five minutes. Blood loss was estimated at $800 \mathrm{ml}$, and a total of $2000 \mathrm{ml}$ warmed normal saline was given during the procedure. Oxytocin $20 \mathrm{I}$.U. was added to the intravenous fluid at delivery. Postoperative analgesia was provided by three milligram preservativefree epidural morphine, administered after clamping of the umbilical cord. Mother and child had an uneventful postoperative course. There was no untoward reaction to the morphine.

\section{Discussion}

Monoamine oxidase (MAO) is one of two principal enzymes involved in the deamination of neurotransmitters, and two sub-types have been identified. One is MAOA, which preferentially deaminates 5 -hydroxytryptamine (5-HT), norepinephrine and epinephrine. The other is MAO-B, which preferentially deaminates nonpolar aromatic amines. New generation MAOIs bind specifically with MAO-A, have short half-lives and can be displaced by other substrates, e.g., tyramine. McFarlane has recently reviewed the new MAOIs. ${ }^{4}$

Phenelzine is a first generation MAOI and binds irreversibly with both MAO-A and MAO-B. As synthesis of new MAO takes weeks, interactions can continue to occur even if the drug is stopped. The interaction of most concern is that involving MAOI and opioids, notably meperidine. There are two forms of interaction: Type I is excitatory and thought to be due to serotonergic overactivity. It is characterised by agitation, headache, rigidity, hyperthermia, convulsions and coma. Meperidine is thought to be the only commonly used opioid to elicit such a reaction. Type II is depressive, characterised by hypotension, respiratory depression and coma.

Rivers and Horner ${ }^{5}$ reported a death involving an interaction between dextromethorphan, which blocks neur- 
onal 5HT uptake, and phenelzine. This drug is not in common use in anaesthesia. There are no reports of morphine producing type I interactions with MAOI, and it was used uneventfully in the woman in this report. As she had twice received fentanyl in the past without incident, this drug could have been added to the bupivacaine infusion, allowing a lower total dose of bupivacaine. It also would have been useful in the management of perineal pain or back pain.

Alfentanil is another drug reported to be safe ${ }^{6}$ although experience with this drug in the epidural space is limited. Meperidine is the only opioid commonly used by anaesthetists which produces fatal excitatory interactions. As pointed out in the review of MAOI by Stack, Rogers and Linter, ${ }^{3}$ the practice of giving test doses, as described by Churchill-Davidson, ${ }^{7}$ is unnecessary as opioids other than meperidine can be used safely.

The other area of concern in patients receiving MAOIs is the selection of pressor agents. Hypotension is common with regional anaesthesia. It usually responds to fluid administration but pressor agents may be required, especially if there is a rapid, precipitous decrease in blood pressure. Ephedrine has been the pressor agent of choice in obstetric patients for $25 \mathrm{yr}$. It is thought to act more by increasing cardiac output (a $\beta$ effect) than by increasing systemic vascular resistance (an $\alpha$ effect). ${ }^{8}$ The latter effect also increases uterine vascular resistance, reducing uterine perfusion. Ephedrine also constricts uterine vessels but has a more selective effect on systemic vessels than other agents, e.g., metaraminol. ${ }^{9}$

Ephedrine and metaraminol are indirectly acting pressor agents. Treatment with MAOI leads to accumulation of norepinephrine in sympathetic nerve terminals, and indirectly acting agents can release large quantities of this and other neurotransmitters. This results in an exaggerated, hypertensive response to these drugs which may require treatment with alpha-adrenoreceptor blockade, e.g., phentolamine. ${ }^{10}$ Although phenylephrine is generally considered a direct-acting agent, it also has some indirect action and is contra-indicated in these patients.

Although normally considered contra-indicated as treatment for hypotension prior to delivery of the fetus (due to uterine artery vasoconstriction), direct-acting agents, such as infusions of epinephrine, norepinephrine or isoprenaline, would be the pressor agents of choice in the parturient on MAOIs. These agents must be used with caution as there may be receptor hypersensitivity. ${ }^{11}$

In conclusion, we feel that epidural anaesthesia is the anaesthetic of choice in the parturient receiving MAOIs. The presence of an epidural catheter means that the problems of general anaesthesia in these patients can usually be avoided. There has to be careful intravenous fluid loading, careful establishment of the block, avoidance of mep- eridine and of indirectly acting pressor agents in the treatment of hypotension. Pregnant women receiving MAOIs should continue to take their medication.

\section{References}

1 Shee JC. Dangerous potentiation of pethidine by iproniazid, and its treatment. BMJ 1960; 2: 507-9.

2 Vigran IM. Dangerous potentiation of meperidine hydrochloride by pargyline hydrochloride. JAMA 1964; 187: 953-4.

3 Stack CG, Rogers P, Linter SPK. Monoamine oxidase inhibitors and anaesthesia. A review. Br J Anaesth 1988; 60: 222-7.

4 McFarlane HJ. Anaesthesia and the new generation monoamine oxidase inhibitors. Anaesthesia 1994; 49: 597-9.

5 Rivers $N$, Homer $B$. Possible lethal reaction between Nardil and dextromethorphan (Letter). Can Med Assoc J 1970; 103: 85 .

6 Powell $H$. Use of alfentanil in a patient receiving monoamine oxidase inhibitor therapy (Letter). Br J Anaesth 1990; 64: 528 .

7 Churchill-Davidson HC. Anaesthesia and monoamine oxidase inhibitors (Letter). BMJ 1965; 1: 520.

8 James FM III, Greiss FC Jr, Kemp RA. An evaluation of vasopressor therapy for maternal hypotension during spinal anesthesia. Anesthesiology 1970; 33: 25-34.

9 Tong $C$, Eisenach JC. The vascular mechanism of ephedrine's beneficial effect on uterine perfusion during pregnancy. Anesthesiology 1992; 76: 792-8.

10 Stockley IH. Drug Interactions: A Source Book of Adverse Interactions, Their Mechanisms, Clinical Importance and Management. Oxford: Blackwell Scientific Publications, 1981.

11 Boakes AJ, Laurence DR, Teoh PC, Barar FSK, Benedikter $L T$, Prichard BNC. Interactions between sympathomimetic amines and antidepressant agents in man. BMJ 1973; 1: 311-5. 